\title{
Attitude Towards Drug Therapy in a Community Mental Health Center Evaluated by the Drug Attitude Inventory
}

This article was published in the following Dove Press journal: Patient Preference and Adherence

\author{
Rosaria Di Lorenzo $\mathbb{D D}^{\prime}$ \\ Daniela Perrone ${ }^{2}$ \\ Anushree Montorsi ${ }^{3}$ \\ Jessica Balducci $\mathbb{D}^{4}$ \\ Sergio Rovesti (D) $^{5}$ \\ Paola Ferri (iD) ${ }^{6}$ \\ 'Mental Health and Drug Abuse \\ Department of AUSL-Modena, \\ Psychiatric Intensive Treatment Facility, \\ Modena 4I I22, Italy; ${ }^{2}$ Mental Health \\ Department, UOC Psychiatry, Fermo \\ 63900, Italy; ${ }^{3}$ School of Nursing, \\ University of Modena and Reggio Emilia, \\ Modena 4I I24, Italy; ${ }^{4}$ School of \\ Specialization in Psychiatry, University of \\ Modena and Reggio Emilia, Modena \\ 4I I24, Italy; ${ }^{5}$ General and Applied \\ Hygiene, Department of Biomedical, \\ Metabolic and Neural Sciences, Public \\ Health Section, Modena, 4I I25, Italy; \\ ${ }^{6}$ Nursing, Department of Biomedical, \\ Metabolic and Neural Sciences, Public \\ Health Section, Modena, 4II25, Italy
}

Correspondence: Rosaria Di Lorenzo Email saradilorenzol@alice.it
Introduction: Negative attitude towards drug therapy can foster limited adherence to treatment, which remains one of the biggest obstacles for implementing effective treatments, especially long term.

Purposes: The purposes of the study were 1) to evaluate the attitude towards drug therapy among a representative sample of patients treated in a community psychiatric service using 30-item Drug Attitude Inventory (DAI-30); 2) to evaluate the DAI-30 dimensions, applying factorial analysis; and 3) to highlight the socio-demographic and clinical variables correlated to DAI-30 score and factors.

Methods: The DAI was administered, over a 7-month period, to all patients treated in our psychiatric outpatient services who agreed to participate in this study and provided their informed consent. Data were statistically analyzed.

Results: With a response rate of $63.3 \%, 164$ females and 136 males completed the DAI-30 with an average score of $14.24( \pm 10.46 \mathrm{SD})$, indicating moderately positive attitude towards drug therapy. The analysis of DAI-30 internal consistency confirmed its reliability (Cronbach's alpha $=0.84$ ). Our factorial analysis highlighted three factors: Factor 1 (Cronbach's alpha $=0.81$ ), composed of 7 items which indicate positive, trustful attitude; Factor 2 (Cronbach's alpha=0.78), composed of 5 items indicating negative attitude of suspiciousness; and Factor 3 (Cronbach's alpha=0.66), composed of 4 items suggesting defensive and control attitude towards drug therapy.

Discussion: Among the selected variables, "monotherapy" and "total number of hospitalizations" were negatively correlated to the final score of DAI-30, whereas being "married" was positively correlated to it, in a statistically significant way, using the multiple linear regression model. These correlations suggest that positive attitude towards drug therapy could be reinforced by the condition of being married and reduced by relapses with hospitalization, as literature highlighted, and, paradoxically, by a monotherapy, which could suggest a sort of psychological dependence on therapy and, indirectly, on psychiatric service, potentially correlated to the long-term treatments of our patients.

Keywords: attitude towards drugs, psychiatric disorders, community mental health center, therapy adherence

\section{Introduction}

The lack of adherence to a therapeutic regimen is a complex and multifactorial phenomenon and has constituted a well-known challenge since the dawn of medicine. ${ }^{1}$ The World Health Organization identified some factors of treatment non-adherent behaviour: socio-economic and clinical characteristics of patients, 
type of therapy and treatment, quality of the relationship between professional and patient, other psychosocial characteristics of environment. ${ }^{1}$ Between one-third and onehalf of drugs prescribed for chronic or long-term conditions are not taken by patients according to the indications of the prescribers. ${ }^{2}$ Adherence is greater in patients who have an acute illness than in those who suffer from a chronic illness. ${ }^{3}$ Poor therapeutic adherence is a complex problem, often persistent and resistant to "generic" approaches, ${ }^{4-6}$ which requires complex interventions to improve the overall quality of care. ${ }^{5-7}$ Poor adherence to treatment represents the main cause of suboptimal clinical outcome in all diseases, ${ }^{8,9}$ resulting in inefficient utilization of economic resources.

In psychiatric practice, the lack of adherence to treatment appears to be correlated both to the patient's attitude towards therapy, such as distrust, ambivalence, rejection for unpleasant undesirable effects, and to the state of illness that, if acute and severe, can favour the refusal of drug intake. The patient who does not adhere to treatment can induce in the therapist feelings of impotence and frustration, which can favour excessive pharmacological prescription, interpreted as an expression of the so-called "counter-transference desperation". ${ }^{10}$ In psychiatry, the patient often presents, at the same time, "continuous" symptoms and "discontinuous" relationship with treatment. ${ }^{11}$ A historical review of adherence in psychiatric disorders compared with organic ones, ${ }^{12}$ showed lower adherence rates in patients taking antipsychotic drugs (58\%), compared to those who took treatments for physical disorders $(76 \%)$, although this result could have been biased due to different methodologies for measuring the therapeutic adherence. ${ }^{12}$ Recently, a systematic review of 39 studies reported an average rate of non-adherence in schizophrenia patients of $41 \%$, which would increase to $50 \%$ when the analysis is restricted to more methodologically rigorous studies. ${ }^{13}$ It has been observed that about $75 \%$ of patients with schizophrenia stopped taking the drugs within 2 years following the first hospital discharge. ${ }^{14}$ In 2002, Rossi et al ${ }^{15}$ identified three critical factors for therapeutic adherence related to person (attitudes, judgments, personality traits, personal beliefs), treatment (side effects and tolerability, complexity of treatment, doctor-patient relationship, efficacy of treatment, attitudes of rejection of therapy) and pathology (lack of insight, grandiosity, depressive symptoms, cognitive deficits). The conceptualisation of medication adherence is complex and, in accordance with some authors, illness and treatment-related subjective attitudes may be more relevant for collaboration in outpatient antipsychotic drug treatment than side effects, cognitive functioning or any socio-demographic variable. ${ }^{16}$ Although continued use of anti-psychotic treatment after symptom remission is sustained by most guidelines, poor therapeutic adherence remains the major obstacle for the treatment of patients with schizophrenia and other psychoses. ${ }^{17} \mathrm{~A}$ recent systematic review has estimated at $3 \%$ the one-year recurrence rate for patients who continued antipsychotics whereas the risk of recurrence is increased to over $90 \%$ among patients who had discontinued antipsychotic therapy within 2 years. ${ }^{18}$ There is a general consensus on the fact that lack of adherence represents the major criticality in treatments, especially long-term ones, in the most severely ill patients ${ }^{19}$ with further negative repercussions on both the patient's quality of life and Mental Health Services. ${ }^{20}$ One of the most immediate consequences of lack of adherence is a high rate of relapse, which can favour the so-called "revolving door" phenomenon. ${ }^{21}$ Patients with relapses have a greater risk of self-injurious behaviour, increased suicide and death rates, greater difficulty in re-entering the workforce and risk of remaining dependent on their families, ${ }^{22}$ with worsening of quality of life and family and social relationships. ${ }^{23,24}$ In turn, as the CUTLASS study showed, the best adherence derives from a better quality of life. ${ }^{25}$ Although most studies are based on populations affected by schizophrenic spectrum disorders, similar difficulties in maintaining drug treatment for a long period are present in patients affected by bipolar disorders $^{26,27}$ and other mood disorders. ${ }^{28}$ A more recent systematic review, after having analysed 36 prospective and observational articles, divided the non-adherence factors in severe psychiatric illnesses into "intentional and unintentional". ${ }^{29}$ Among intentional non-adherence, the significant variables were the degree of illness insight, the attitude towards drugs and the therapeutic alliance. More detailed analyses that explored the relationship between these variables suggested that the positive effect of insight or disease awareness and therapeutic alliance on adherence is indirect and likely mediated by positive attitude and judgement towards drug therapy. ${ }^{30-32}$ Another study highlighted a complex relationship between side effects and adherence characterized by correlations of opposite polarity that "compete" with each other; on the one hand, the deterrent impact of unpleasant adverse effects and on the other the patient's willingness to tolerate them in exchange for beneficial effects. ${ }^{33}$ Regarding the 
unintentional factors of non-adherence, the use or abuse of substances represents the variable most consistently identified by literature reviews, regardless of the type and stage of psychiatric pathology. ${ }^{24,34-37}$ Lack of family and/or social support are other factors that could contribute to unintentional non-adherence; on the other hand, the positive attitude of family members towards therapy and their active involvement in the treatment of schizophrenia patients are significantly associated with positive adherence. $^{30,38}$ Good social support, such as the presence of valid family assistance, helps the patient in taking therapy, reducing the negative effect of substance abuse or other factors. ${ }^{39}$ A pilot study by Sapra et $\mathrm{al}^{40}$ highlighted that the group of patients with psychosis at onset having a good therapeutic relationship with caregivers are more adherent to therapy than the group of patients with multi-episodic schizophrenia. A more recent study has highlighted that treatment adherence among patients suffered from psychiatric disorders cannot be significantly influenced by socio-demographic or clinical factors only, but rather by attitudes toward medications, perceptions of personal necessity for medication and concerns about its potential adverse effects. ${ }^{28} \mathrm{~A}$ recent study has confirmed that patients' attitudes towards their medication influence drug adherence in severe psychiatric patients. ${ }^{41}$ As recently reported by some authors, the therapeutic adherence can be significantly associated with illness insight and "perceived treatment-related trauma" related to previous treatment experiences. ${ }^{42} \mathrm{~A}$ recent review on this topic has reported that only long-term or pragmatic interventions focused on medication adherence showed successful outcomes. ${ }^{43}$

\section{Drug Attitude Inventory}

The Drug Attitude Inventory (DAI) is a self-completed questionnaire composed of 30 items (True/False), DAI30 , on the effects of treatment with psychotropic drugs, helping to identify the target of the pharmacotherapy management. ${ }^{44}$ In 2001, a validation study of the Italian version of the DAI-30 highlighted that the Italian version maintained the psychometric properties of the original questionnaire. ${ }^{45}$ The initial exploratory factor analysis, although carried out in a relatively small sample, highlighted the same factors evidenced by the DAI authors. ${ }^{45}$

The questionnaire was subsequently validated in Korean ${ }^{46}$ and in Turkish; ${ }^{47}$ its reduced 10 -item version was used in an Egyptian study. ${ }^{48}$ In Tunisia, it was validated by the study of Nakhli et al, ${ }^{49}$ which examined a sample of 204 outpatients with schizophrenia, reporting 7 factors responsible for $59.9 \%$ of the overall variance, with a Cronbach's alpha of 0.88 . The DAI-30 was used in numerous studies as a questionnaire for predicting adherence in schizophrenia and major depression patients. Townsend et $\mathrm{al}^{50}$ used DAI-30 in a sample of 122 adolescent patients diagnosed with heterogeneous psychiatric disorders, where the questionnaire was shown to be a valid tool even changing the dichotomous answers True or False to ones ranged between 1 and 5 in a Likert scale. Balestrieri et $\mathrm{al}^{51}$ analyzed the attitude towards therapy using the DAI-30 in a homogeneous for pathology sample of 145 patients treated in monotherapy with five different antipsychotics. Similarly, a cross-sectional analysis $^{52}$ using the reduced version DAI-10 in 291 patients with schizophrenia highlighted that only some variables, such as family support, insight of illness, therapeutic alliance and number of psychiatric hospitalizations, significantly influenced drug attitude. Recently, the reduced version DAI-10 administered to 60 patients with schizophrenia showed that the group with the greatest therapeutic adherence was that in which individualized interventions had been implemented to encourage a positive drug attitude. ${ }^{53}$

\section{Purposes of the Study}

The main objective of the present study is to evaluate the attitude towards drug therapy of patients treated in an outpatient psychiatric service using the DAI-30.

The secondary objectives are to evaluate the DAI-30 dimensions, applying factorial analysis, and to highlight the demographic and clinical variables correlated to DAI-30.

\section{Materials and Methods}

\section{The Sample}

The sample is represented by the patients treated in a Community Mental Health Center (CMHC) located in a Northern Italian city, during the period of data collection (from $8 / 9 / 2018$ to $8 / 4 / 2019$ ), according to our inclusion and exclusion criteria.

Inclusion criteria:

- All patients pharmacologically treated in our CMHC during the study period who agreed to participate in the study. 
- All the above who provided, or whose legal guardian provided, written informed consent to the study.

Exclusion criteria:

- Patients not pharmacologically treated in the CMHC.

- Patients on first consultation in the CMHC.

- Patients unable to provide valid consent.

In order to collect a sample numerically representative of our population, we calculated a sample size of 330 individuals from the population of 2,320 patients treated in 2018 at our $\mathrm{CMHC}$, with a margin of error of $5 \%$, assuming a level of bilateral significance $(\alpha)$ of 0.05 and confidence interval of $95 \%$.

\section{Design of the Study}

This is a cross-sectional observational pilot study, carried out by administering the DAI-30, already translated and validated in Italian. ${ }^{45}$ The test was administered to patients during CMHC opening hours from Monday to Saturday. Patients were enrolled by two researchers authorized by the Ethics Committee, who did not treated the study patients. If participants were unable to independently complete the DAI-30, the questionnaire was administered by the researcher. Subsequently, the same researcher completed the form with the socio-demographic and clinical variables of participants.

\section{DAl-30}

The criterion for scoring the questionnaire described by its authors ${ }^{44}$ includes a total of 30 questions, 15 positive (the expected responses will be $\mathrm{T}$ ), which assess adherence, and 15 negative (whose expected answers will be F), which evaluate non-adherence. The sum of the obtained score is expressed in a whole number ranged between -30 and $+30 .^{44}$

The original version of DAI includes 30 items (DAI30), which are distributed over 7 factors, according to the validation study of the authors who built the scale. ${ }^{44}$ Factor 1 contains items that express feelings of wellbeing that the patient attributes to the effects of drugs. Factor 2 represents the negative effects that the patient attributes to drugs; the sum of the items of these two factors identifies a construct called "subjective response to treatment". The remaining five factors constitute "attitudes and opinions" that are considered important in determining therapeutic adherence: Factor 3 can be interpreted as the patient's idea of health or illness (for example, the pills are taken when one is sick and not when one is well); Factors 4 and 5 include items that express the patient's attitude regarding the control of therapy intake; Factor 6 consists of two items formulated to indicate what the patient believes on drug efficacy to prevent relapses; Factor 7 concerns potential toxic effects. The sum of the items of these last five factors identifies a construct called the "attitude towards therapy". As reported in the work of the authors of the questionnaire, Hogan et $\mathrm{al}^{44}$ the DAI-30 can therefore be divided into two sub-scales, one of the 14 items and the other of 11 . The remaining 5 items are omitted from the evaluation. The first sub-scale, which includes Factors 1 and 2, evaluates the "subjective response to treatment"; the second, which includes the remaining five factors, assesses the "attitude towards therapy".

\section{Selected Variables}

1. Socio-demographic variables: age, sex, nationality, marital status, schooling, work, living environment.

2. Clinical variables: psychiatric diagnosis according to ICD-9-CM (International classification of diseases, 9th revision, Clinical modification), ${ }^{54}$ number of psychiatric hospitalizations, time since the last admission, period of care at $\mathrm{CMHC}$, prescribed drugs, modality of drug administration, mono/polytherapy, organic comorbidity, treatment in other community services.

For each patient, the aforementioned variables were retrospectively collected from patient medical records and from informatics database at $\mathrm{CMHC}$ and, after the anonymization of personal data, inserted in an Excel database.

\section{Statistical Analysis}

We applied descriptive statistical analysis of the variables: mean and standard deviation (SD) for continuous variables; percentages for categorical variables. After having applied skewness and kurtosis test for normality, we analysed continuous variables normally distributed using $t$-test and applied non-parametric method (Kruskal Wallis test) for analysing continuous variables not normally distributed. We analysed categorical variables using Pearson's chi-square test.

Cronbach's alpha coefficient was applied to highlight the internal consistency of DAI-30 in Italian version.

An exploratory factor analysis (EFA) was applied to DAI-30 score, to preliminarily investigate the factors 
underlying the scale. The conventional approach of principal factor analysis was used, followed by orthogonal (varimax) and oblique (promax) rotation. ${ }^{55,56}$ To verify the appropriateness of the analysis performed with the orthogonal rotation, the oblique rotation of the factors was carried out, which made it possible to assess the interdependence of the factors themselves. The factors highlighted by the orthogonal rotation were selected on the basis of a dual criterion: eigenvalue $>1$ for each factor (Kaiser's criterion), ${ }^{57}$ subsequently confirmed by the scree-plot. The items with factor loadings $>0.40$ on a given factor were therefore identified as "good indicators of a factor". The greater the factor loading, the more relevant the variable related to the factor. The KaiserMeyer-Olkin (KMO) test ${ }^{58}$ was used to verify the suitability of the sample for application of the factor analysis and Bartlett's spherical test to verify the applicability of the factor analysis in our sample.

For each factor the internal consistency was calculated by means of Cronbach's alpha coefficient.

The DAI-30 score and the score of the items underlying the factors were correlated with the selected variables through a multiple linear regression test, stepwise model. We applied the backward stepwise selection, considering variables for removal from the model if their p-value was $\geq 0.2$ and would reconsider previously deleted variables for re-entry if their p-value was $<0.1$.

A $p<0.05$ and two-sided alpha level of 0.05 were used as the probability statistic level of significance. The statistical analysis was conducted through the STATA 12 software program version (2011).

\section{Ethical Considerations}

The present research was conducted in accordance with the principles of the Helsinki Declaration (World Medical Association, 1964) and good clinical practice. The study was approved by the Ethics Committee of the "Area Vasta Emilia Nord" (Prot. no. AOU 0023224/18 of 19-9-2018) and was authorized by the local Department of Mental Health and Drug Abuse (Decision no. 1843 of 5-10-2018). Informed written consent was obtained from each patient or their legal guardian before his/her participation in this study.

\section{Results}

\section{Our Sample}

During the data collection period, 300 participants, 164 females and 136 males, among the 474 patients who were asked to participate in the study, agreed to correctly complete the DAI-30, after having provided their informed consent, with an overall response rate of $63.3 \%$. In Figure 1, the flow diagram of participants screened is shown. The sample size is numerically close to the appropriate size to represent the population of 2,320 patients treated in our CMHC in 2018.

\section{The Selected Variables}

Regarding the socio-demographic variables (Table 1), our participants were 48.54 years old (minimum 18, maximum 85 ), without a statistically significant difference between the two genders ( $\mathrm{p}=0.65$, Skewness/Kurtosis tests; $t=1.88$, $\mathrm{p}=0.061, t$-test). The majority of them was Italian (87\%), $38 \%$ were employed, most of them had attended a middle (37\%) or high school (37\%), without a statistically significant difference between the two genders; regarding marital status, women were more frequently married than men (Pearson chi $2=17.66, \mathrm{p}<0.001$ ) and lived in the marital family in higher percentage than men (Pearson chi2 $=16.59$, $\mathrm{p}=0.002$ ).

We did not highlight any statistically significant difference between the two genders regarding the clinical variables shown in Table 2. The patients of our sample had quite a long history of psychiatric illness, being in care at our CMHC for more than 10 years in $40 \%$ of cases. Most of our patients $(73 \%)$ were treated only in our community services. Among the psychiatric diagnoses, schizophrenic disorders and other psychoses were prevalent (34\%), followed by bipolar disorders (22\%), personality disorders (17\%), neurotic disorders (14\%), adjustment reactions (7\%) and alcohol and/or drug-induced mental disorders (1\%). An organic comorbidity was present in $45 \%$ of our sample. Without any statistically significant difference between the two genders, the majority of our sample (83\%) had not been hospitalized in a psychiatric ward in the previous year $(p<0.001$, Skewness/Kurtosis tests; males vs females, $p=0.699$, Kruskal-Wallis test) and each patient had an average 1.74 psychiatric hospitalizations from the illness onset $(\mathrm{p}<0.001$, Skewness/Kurtosis tests; males vs females, $p=0.299$, Kruskal-Wallis test).

All patients in our sample were taking drug therapy at the time of DAI-30 administration, according to the inclusion criteria. Most patients took an oral therapy (88\%), consisting mainly of antipsychotics (66\%), which, in the different formulations (oral, depot) are the most represented drugs in our sample, followed by benzodiazepines and antidepressants $(60 \%)$ (Table 3). Both antidepressants (Pearson chi2 $=21.61$, 


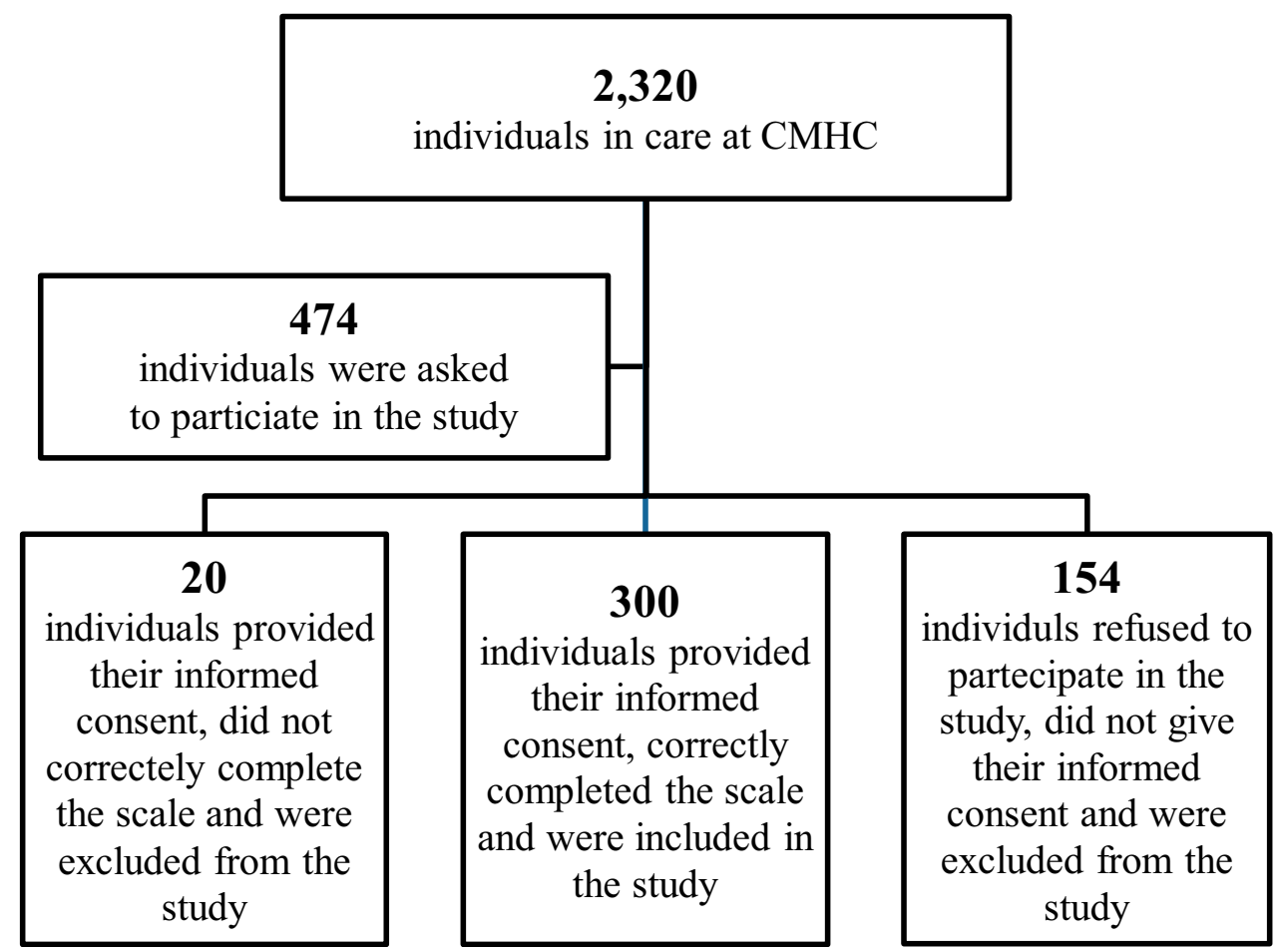

Figure I The flow diagram of participants screened.

$\mathrm{p}=0.004$ ) and benzodiazepines (Pearson chi2 $=8.24, \mathrm{p}<0.001$ ) were most often prescribed in females. Polytherapy was prescribed to most of our patients ( $81 \%)$, more often prescribed to women compared to men (Pearson chi2 $=8.12, \mathrm{p}=0.004$ ).

\section{The Analysis of DAI-30}

We obtained an average score of $14.24( \pm 10.46 \mathrm{SD})$, with a range between -26 and +30 .

In Figure 2, the sum of each item score across patients is shown.

We reported the lowest scores in the items 11, 12, 21 and 24 (Figure 2).

The Cronbach's alpha coefficient associated with the totality of the 30 items was 0.84 , indicating a good reliability and internal consistency of the DAI-30 (item-test correlation $=0.14$ ).

Our sample of 300 participants proved to be numerically sufficient for validation analysis, since 10 individuals per item are recommended by most statisticians ${ }^{59}$ or in accordance with the "Rule of 5" (rule of thumb), which foresees a minimum of 5 individuals per item. ${ }^{60}$

Our EFA highlighted 3 factors with eigenvalue $>1$, according to the Kaiser's criterion, ${ }^{57}$ able to explain $79 \%$ of the variance of our sample. This result was successively confirmed by the scree-plot (Figure 3). On the orthogonal rotation (varimax) (Table 4), all but 14 items of the DAI30 presented factor loadings $>0.40$, distributed in the first three factors. As shown in Table 4, the three factors are loaded by 16 items with uniqueness values ranging from 0.38 to 0.70 . The first factor, which explains $46 \%$ of variance, is loaded by the greatest number of items ( 7 items out of 30); the second factor, loaded by 5 items, explains $20 \%$ of the variance; the third factor, explaining $13 \%$ of variance, is loaded by 4 items. The oblique rotation substantially showed that Factors 1, 2 and 3 were positively correlated among themselves and explained $35 \%, 26 \%$ and $25 \%$ of variance respectively, for a total variance of $86 \%$ (promax matrix).

The three factors we highlighted at EFA indicated the following domains: the first factor, loaded by 7 items, a positive attitude of trust and hope; the second factor, loaded by 5 items, a negative attitude of suspicion and harm; the third factor, loaded by 4 items, a defensive and rational attitude towards drug therapy (Figure 4). Factor 1 showed good (Cronbach's alpha $=0.81$ ) and Factor 2 showed acceptable internal consistency (Cronbach's alpha $=0.78$ ), whereas Factor 3 presented questionable 
Table I Socio-Demographic Variables of Our Sample

\begin{tabular}{|c|c|c|c|}
\hline \multirow[t]{2}{*}{ Variables } & \multicolumn{3}{|l|}{ Sample } \\
\hline & $\begin{array}{l}\text { Male } \\
N=136 \\
(45 \%)\end{array}$ & $\begin{array}{l}\text { Female } \\
N=164 \\
(55 \%)\end{array}$ & $\begin{array}{l}\text { Total } \\
N=300 \\
(100 \%)\end{array}$ \\
\hline \multicolumn{4}{|c|}{ Age, mean \pm standard deviation } \\
\hline Years & $\begin{array}{l}46.83 \\
\pm 14.26\end{array}$ & $\begin{array}{l}49.96 \\
\pm 14.38\end{array}$ & $\begin{array}{l}48.5 \\
\pm 14.39\end{array}$ \\
\hline \multicolumn{4}{|l|}{ Nationality, n (\%) } \\
\hline $\begin{array}{l}\text { Italian } \\
\text { European (no-Italian) } \\
\text { Extra-European }\end{array}$ & $\begin{array}{l}120(88 \%) \\
0(0 \%) \\
16(12 \%)\end{array}$ & $\begin{array}{l}142(86 \%) \\
6(4 \%) \\
16(10 \%)\end{array}$ & $\begin{array}{l}262(87 \%) \\
6(2 \%) \\
32(11 \%)\end{array}$ \\
\hline \multicolumn{4}{|l|}{ Marital status, n (\%) } \\
\hline $\begin{array}{l}\text { Single } \\
\text { Married } \\
\text { Divorced or widowed }\end{array}$ & $\begin{array}{l}77(58 \%) \\
44(32 \%) \\
14(10 \%)\end{array}$ & $\begin{array}{l}55(34 \%) \\
70(43 \%) \\
37(23 \%)\end{array}$ & $\begin{array}{l}132(44 \%) \\
114(38 \%) \\
51(18 \%)\end{array}$ \\
\hline \multicolumn{4}{|l|}{ Schooling, n (\%) } \\
\hline $\begin{array}{l}\text { Elementary school } \\
\text { Middle school } \\
\text { High school } \\
\text { University degree } \\
\text { Unknown }\end{array}$ & $\begin{array}{l}14(10 \%) \\
51(37.5 \%) \\
51(37.5 \%) \\
11(8 \%) \\
9(7 \%)\end{array}$ & $\begin{array}{l}17(10 \%) \\
59(36 \%) \\
59(36 \%) \\
21(13 \%) \\
8(5 \%)\end{array}$ & $\begin{array}{l}31(10 \%) \\
110(37 \%) \\
110(37 \%) \\
32(10 \%) \\
17(6 \%)\end{array}$ \\
\hline \multicolumn{4}{|l|}{ Work, n (\%) } \\
\hline $\begin{array}{l}\text { Employed } \\
\text { Unemployed } \\
\text { Retired for disabilty } \\
\text { Retired for age } \\
\text { Student } \\
\text { Unknown }\end{array}$ & $\begin{array}{l}51(38 \%) \\
44(32 \%) \\
20(15 \%) \\
11(8 \%) \\
7(5 \%) \\
3(2 \%)\end{array}$ & $\begin{array}{l}62(38 \%) \\
50(30 \%) \\
20(12 \%) \\
20(12 \%) \\
8(5 \%) \\
4(3 \%)\end{array}$ & $\begin{array}{l}113(38 \%) \\
94(31 \%) \\
40(13 \%) \\
31 \text { (11\%) } \\
15(5 \%) \\
7(2 \%)\end{array}$ \\
\hline \multicolumn{4}{|c|}{ Living environment, n (\%) } \\
\hline $\begin{array}{l}\text { Alone } \\
\text { Parental family } \\
\text { Marital family } \\
\text { Protected facility } \\
\text { Unknown }\end{array}$ & $\begin{array}{l}30(22 \%) \\
44(32 \%) \\
44(32 \%) \\
13(10 \%) \\
5(4 \%)\end{array}$ & $\begin{array}{l}31(19 \%) \\
32(20 \%) \\
88(53 \%) \\
8(5 \%) \\
5(3 \%)\end{array}$ & $\begin{array}{l}61(20 \%) \\
76(26 \%) \\
132(44 \%) \\
21(7 \%) \\
10(3 \%)\end{array}$ \\
\hline
\end{tabular}

internal consistency (Cronbach's alpha $=0.66$ ), just above the minimum threshold of acceptability of item aggregation (0.6), indicating a minor homogeneity of item dimensions.

Further confirmation of the numerical adequacy of our sample for EFA was subsequently obtained by applying the
Table 2 Clinical Variables of Our Sample

\begin{tabular}{|c|c|c|c|}
\hline \multirow[t]{2}{*}{ Variables } & \multicolumn{3}{|l|}{ Sample } \\
\hline & $\begin{array}{l}\text { Male } \\
N=136 \\
(45 \%)\end{array}$ & $\begin{array}{l}\text { Female } \\
N=164 \\
(55 \%)\end{array}$ & $\begin{array}{l}\text { Total } \\
N=300 \\
(100 \%)\end{array}$ \\
\hline \multicolumn{4}{|c|}{ Treatment in other community services, $n$ (\%) } \\
\hline $\begin{array}{l}\text { No treatment in other } \\
\text { community services } \\
\text { Substance Abuse Service } \\
\text { Social Service } \\
\text { Clinical Psychology } \\
\text { Service } \\
\text { Others or more than } \\
\text { one service }\end{array}$ & $\begin{array}{l}100(74 \%) \\
4(3 \%) \\
19(14 \%) \\
10(7 \%) \\
3(2 \%)\end{array}$ & $\begin{array}{l}\text { I I8 (7I\%) } \\
2(2 \%) \\
25(15 \%) \\
18(11 \%) \\
1(1 \%)\end{array}$ & $\begin{array}{l}218(73 \%) \\
6(2 \%) \\
44(15 \%) \\
28(9 \%) \\
4(1 \%)\end{array}$ \\
\hline \multicolumn{4}{|c|}{ Psychiatric diagnoses (ICD-9-CM), n (\%) } \\
\hline $\begin{array}{l}\text { Schizophrenia and other } \\
\text { psychosis } \\
\text { Bipolar disorders } \\
\text { Neurotic disorders } \\
\text { (Dysthymia and anxiety } \\
\text { disorders) } \\
\text { Personality disorders } \\
\text { Alcohol and/or drug } \\
\text { induced mental } \\
\text { disorders } \\
\text { Adjustment reactions } \\
\text { Others }\end{array}$ & $\begin{array}{l}59(43 \%) \\
23(17 \%) \\
15(11 \%)\end{array}$ & $\begin{array}{l}43(26 \%) \\
43(26 \%) \\
27(16 \%)\end{array}$ & $\begin{array}{l}102(34 \%) \\
66(22 \%) \\
42(14 \%)\end{array}$ \\
\hline \multicolumn{4}{|c|}{ Organic comorbidity, n (\%) } \\
\hline $\begin{array}{l}\text { Absent } \\
\text { Present } \\
\text { Not ascertainable }\end{array}$ & $\begin{array}{l}79(58 \%) \\
56(41 \%) \\
I(1 \%)\end{array}$ & $\begin{array}{l}84(51 \%) \\
79(48 \%) \\
I(1 \%)\end{array}$ & $\begin{array}{l}163(54 \%) \\
135(45 \%) \\
2(1 \%)\end{array}$ \\
\hline \multicolumn{4}{|c|}{ Period of treatment in CMHC, n (\%) } \\
\hline $\begin{array}{l}<\mathrm{I} \text { year } \\
\mathrm{I}-10 \text { years } \\
>10 \text { years } \\
\text { Not ascertainable }\end{array}$ & $\begin{array}{l}25(18 \%) \\
55(40 \%) \\
50(37 \%) \\
6(5 \%)\end{array}$ & $\begin{array}{l}27(16 \%) \\
60(37 \%) \\
71(43 \%) \\
6(4 \%)\end{array}$ & $\begin{array}{l}52(18 \%) \\
115(38 \%) \\
121(40 \%) \\
12(4 \%)\end{array}$ \\
\hline \multicolumn{4}{|c|}{$\begin{array}{l}\text { Psychiatric hospitalizations from illness onset, mean } \\
\text { Istandard deviation }\end{array}$} \\
\hline Number & $1.49 \pm 3.83$ & $1.95 \pm 4.43$ & $1.74 \pm 4.17$ \\
\hline \multicolumn{4}{|c|}{ Psychiatric hospitalizations in the previous year, $\mathbf{n}(\%)$} \\
\hline $\begin{array}{l}\text { I or more than one } \\
\text { None } \\
\text { Not ascertainable }\end{array}$ & $\begin{array}{l}19(14 \%) \\
114(84 \%) \\
3(2 \%)\end{array}$ & $\begin{array}{l}27(16 \%) \\
134(82 \%) \\
3(2 \%)\end{array}$ & $\begin{array}{l}46(15 \%) \\
248(83 \%) \\
6(2 \%)\end{array}$ \\
\hline
\end{tabular}


Table 3 Pharmacological Variables of Our Sample

\begin{tabular}{|c|c|c|c|c|}
\hline \multirow{2}{*}{\multicolumn{2}{|c|}{ Variables }} & \multicolumn{3}{|l|}{ Sample } \\
\hline & & $\begin{array}{l}\text { Male } \\
N=136 \\
(45 \%)\end{array}$ & $\begin{array}{l}\text { Female } \\
N=164 \\
(55 \%)\end{array}$ & $\begin{array}{l}\text { Total } \\
N=300 \\
(100 \%)\end{array}$ \\
\hline \multicolumn{5}{|l|}{ Drugs, n (\%) } \\
\hline $\begin{array}{l}\text { Oral and/or long- } \\
\text { acting antipsychotic }\end{array}$ & $\begin{array}{l}\text { Present } \\
\text { Absent }\end{array}$ & $\begin{array}{l}100(74 \%) \\
36(26 \%)\end{array}$ & $\begin{array}{l}99(60 \%) \\
65(40 \%)\end{array}$ & $\begin{array}{l}199(66 \%) \\
101(34 \%)\end{array}$ \\
\hline Mood stabilizer & $\begin{array}{l}\text { Present } \\
\text { Absent }\end{array}$ & $\begin{array}{l}22(16 \%) \\
114(84 \%)\end{array}$ & $\begin{array}{l}34(21 \%) \\
130(79 \%)\end{array}$ & $\begin{array}{l}56(19 \%) \\
244(81 \%)\end{array}$ \\
\hline Benzodiazepine & $\begin{array}{l}\text { Present } \\
\text { Absent }\end{array}$ & $\begin{array}{l}69(51 \%) \\
67(49 \%)\end{array}$ & $\begin{array}{l}110(67 \%) \\
54(33 \%)\end{array}$ & $\begin{array}{l}179(60 \%) \\
121(40 \%)\end{array}$ \\
\hline Antidepressant & $\begin{array}{l}\text { Present } \\
\text { Absent }\end{array}$ & $\begin{array}{l}61(45 \%) \\
75(55 \%)\end{array}$ & $\begin{array}{l}117 \text { (7I\%) } \\
47 \text { (29\%) }\end{array}$ & $\begin{array}{l}178(60 \%) \\
122(40 \%)\end{array}$ \\
\hline Other drugs & $\begin{array}{l}\text { Present } \\
\text { Absent }\end{array}$ & $\begin{array}{l}\text { II (8\%) } \\
125(92 \%)\end{array}$ & $\begin{array}{l}27(16 \%) \\
137(84 \%)\end{array}$ & $\begin{array}{l}38(13 \%) \\
262(87 \%)\end{array}$ \\
\hline \multicolumn{5}{|c|}{ Modality of therapy administration, $n$ (\%) } \\
\hline $\begin{array}{l}\text { Oral } \\
\text { Long-acting } \\
\text { Other or more than }\end{array}$ & modality & $\begin{array}{l}116(85 \%) \\
5(4 \%) \\
15(11 \%)\end{array}$ & $\begin{array}{l}\text { I } 48(90 \%) \\
\text { I (1\%) } \\
15(9 \%)\end{array}$ & $\begin{array}{l}264(88 \%) \\
6(2 \%) \\
30(10 \%)\end{array}$ \\
\hline \multicolumn{5}{|c|}{ Mono- or polytherapy, $\mathbf{n}(\%)$} \\
\hline \multicolumn{2}{|l|}{ Monotherapy } & $\begin{array}{l}36(26 \%) \\
100(74 \%)\end{array}$ & $\begin{array}{l}22(13 \%) \\
142(87 \%)\end{array}$ & $\begin{array}{l}58(19 \%) \\
242(81 \%)\end{array}$ \\
\hline
\end{tabular}

KMO test, ${ }^{58}$ which returned a value of 0.82 , suggestive of a "meritorious" sample (interval between 0.80 and 0.89 ). The distribution of the sample according to Bartlett's spherical test was normal and suitable for the application of the EFA $(p<0.001)$.

\section{The Variables Related to DAI-30 Score}

We did not highlight any statistically significant difference in the DAI-30 score among patients suffering from a schizophrenic spectrum disorder and all other diagnoses ( $\mathrm{p}<0.001$, Skewness/Kurtosis tests; $\mathrm{p}=0.23$, KruskalWallis test) as well as between the two genders $(p=0.65$, Skewness/Kurtosis tests; $\mathrm{p}=0.09, t$-test).

As shown in Table 5, only three variables are statistically significantly correlated with the final score of the DAI-30 using multiple linear regression (stepwise model):

- "married" marital status compared to "single", in positive correlation (being married increases the DAI-30 score),
- number of psychiatric hospitalizations from the illness onset, in negative correlation (a lower total number of admissions is associated with higher scores of the DAI-30),

- monotherapy compared to polytherapy, in negative correlation (monotherapy correlates to potentially worsening perception of drug therapy).

In our stepwise model of multiple linear regression, as seen in Table 5, the variables negatively correlated in a statistically significant way to the three factors of the DAI-30, are the following:

- number of psychiatric hospitalizations from illness onset and the absence of antipsychotic therapy, with Factor 1;

- work activity, represented by the status of "student" and "retired for age", with Factor 2;

- the absence of treatment in other community services, with Factor 3.

\section{Discussion}

This cross-sectional observational 7-month study evaluated the attitude towards drug therapy of people treated at an outpatient psychiatric service using the DAI-30.

The participation of subjects was satisfactory: the average response rate was moderately high, accounting for $63.3 \%$ of respondents. The DAI-30 was easy to read and administer, since only some items were difficult to interpret. In particular, an item on which most respondents asked for clarification was no. 24, which in fact obtained the lowest score. All information and clarifications requested were promptly given. The DAI-30 was administered by a researcher other than each patient's therapist in order to eliminate, as far as possible, a compilation bias.

Our sample is equally distributed between the genders, which show statistically significant differences only in a few socio-demographic and clinical characteristics: women were married and lived in the marital family more often than men, who more frequently remained in their parental family; women were treated with polytherapies and with antidepressants and benzodiazepines more frequently than men. Both these observations overlap those reported in the epidemiological literature. ${ }^{22,61,62}$

Most respondents were affected by schizophrenic and psychotic spectrum disorders (34\%), had suffered from mental disorders for a long time $(40 \%$ of our respondents 


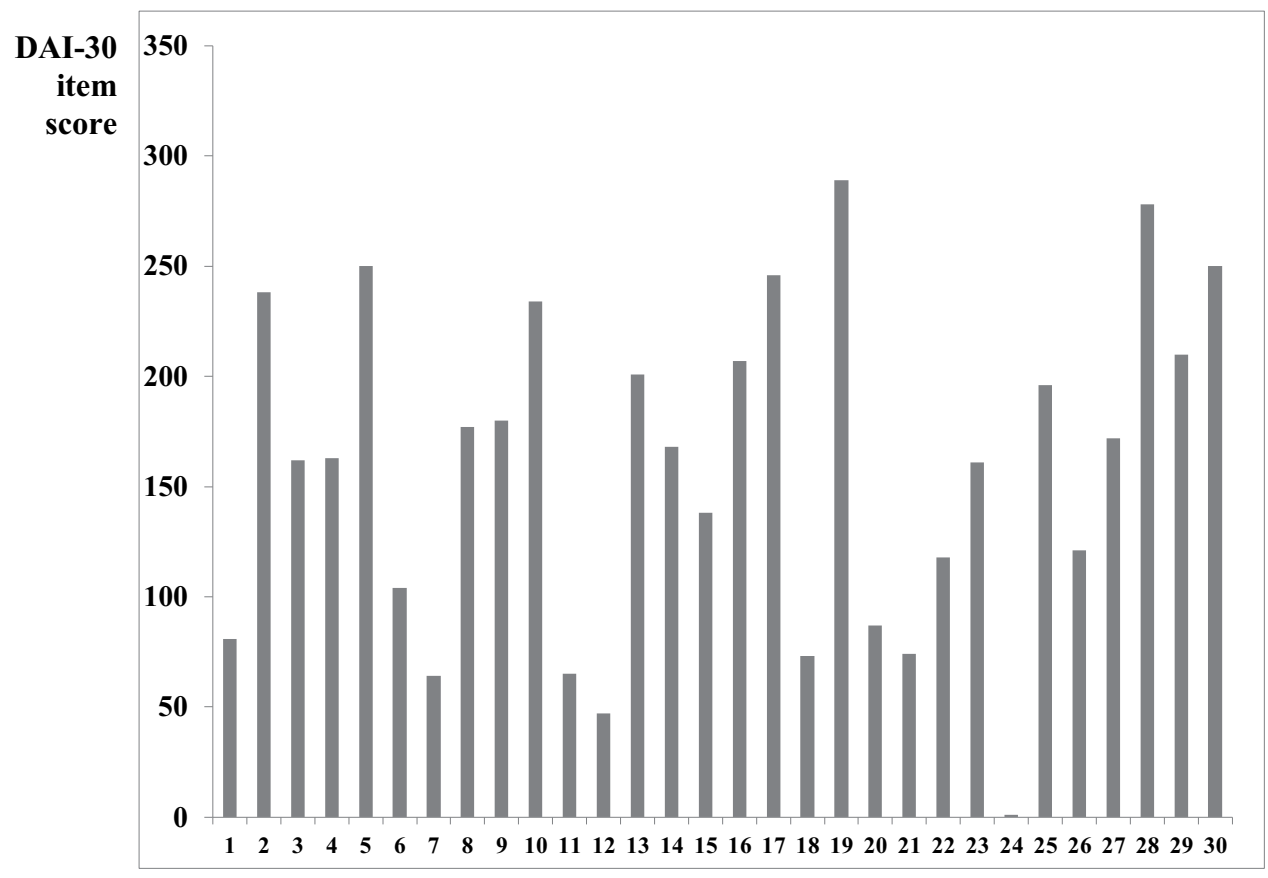

DAI-30 item

Figure 2 The sum of each DAI-30 item score across patients.

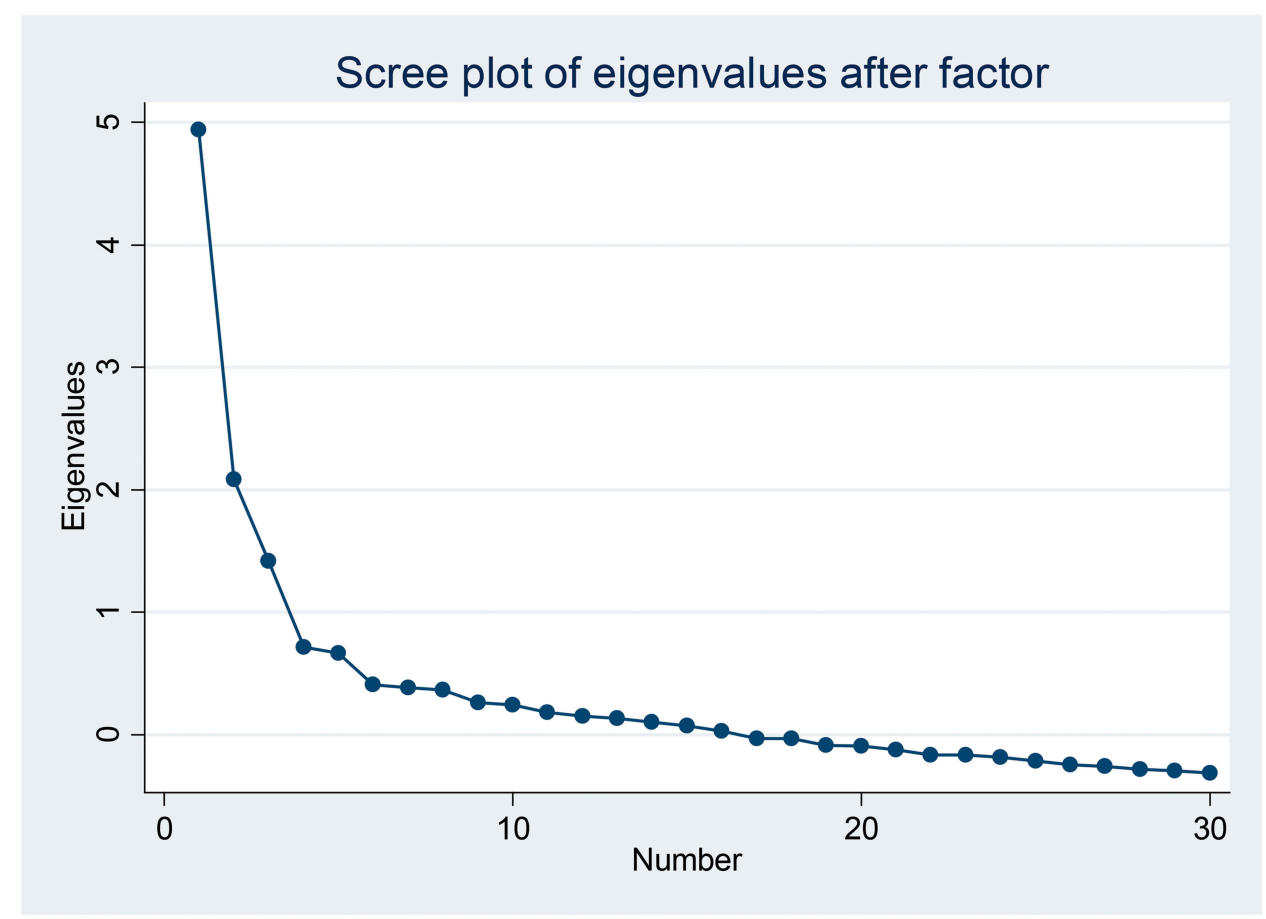

Figure 3 Scree-plot of DAI-30 factorial analysis.

had been treated for more than 10 years), were clinically improved at the moment of the DAI-30 administration ( $83 \%$ of cases had not reported any hospitalization in the previous year). $81 \%$ of our participants were treated with a polytherapy and $88 \%$ with oral therapy, composed of antipsychotics in $66 \%$ of cases. 
Table 4 Factor Loadings $(>0.40)$ and Uniqueness of the DAI-30 Items

\begin{tabular}{|l|l|l|l|l|}
\hline $\begin{array}{l}\text { DAI-30 } \\
\text { Items }\end{array}$ & $\begin{array}{l}\text { Factor I } \\
\text { (Factor } \\
\text { Loading) }\end{array}$ & $\begin{array}{l}\text { Factor 2 } \\
\text { (Factor } \\
\text { Loading) }\end{array}$ & $\begin{array}{l}\text { Factor 3 } \\
\text { (Factor } \\
\text { Loading) }\end{array}$ & Uniqueness \\
\hline Item 1 & & & 0.60 & 0.55 \\
Item 3 & & 0.50 & & 0.53 \\
Item 4 & & & 0.57 & 0.60 \\
Item 6 & 0.65 & & & 0.48 \\
Item 9 & 0.45 & 0.4 I & & 0.60 \\
Item 1I & & 0.64 & & 0.65 \\
Item 12 & & & 0.46 & 0.52 \\
Item 13 & & & & 0.70 \\
Item 15 & 0.70 & 0.63 & & 0.42 \\
Item 16 & & & & 0.50 \\
Item 18 & 0.70 & & 0.43 \\
Item 21 & 0.59 & 0.58 & & 0.50 \\
Item 22 & & & & 0.58 \\
Item 25 & & & & 0.60 \\
Item 26 & 0.74 & & & 0.62 \\
Item 29 & 0.50 & & & \\
\hline
\end{tabular}

Our study, similar to other studies, ${ }^{50,63}$ evaluated drug attitude using the DAI-30 in a large sample with heterogeneous diagnoses and care needs, which is representative of the population treated in an Italian outpatient psychiatric service as highlighted by their socio-demographic and clinical characteristics. ${ }^{64}$ Analysis of the reliability and internal consistency of the DAI-30 questionnaire confirmed that it is a reliable tool (Cronbach's coefficient associated with the totality of the 30 items is equal to 0.84 ), as highlighted by other studies. ${ }^{44,45}$

In accordance with our factorial analysis, the DAI-30 is composed of three factors, supported by 16 items with $>0.40$ factor loadings, which, albeit fewer, overlap the psychological dimensions of those identified in the first validation (7 factors). ${ }^{44}$ In particular, the first factor we identified is loaded by the same items which loaded the Factor 1 identified by Hogan et al, ${ }^{44}$ defined by the DAI30 authors "Subjective positive experience"; the second factor is loaded by the same 5 items loading the Factor 2 identified by Hogan et al, ${ }^{44}$ who named it "Subjective negative experience"; our two factors explain the majority of variance $(66 \%)$ as did the first two factors identified by the DAI-30 authors (75\%). Our third factor is loaded by 4 items that indicate a defensive and control attitude about drug therapy; two of these 4 items (items no. 1 and 13) are the same ones that loaded the third factor identified by Hogan et al, ${ }^{44}$ who defined it "Health/illness",

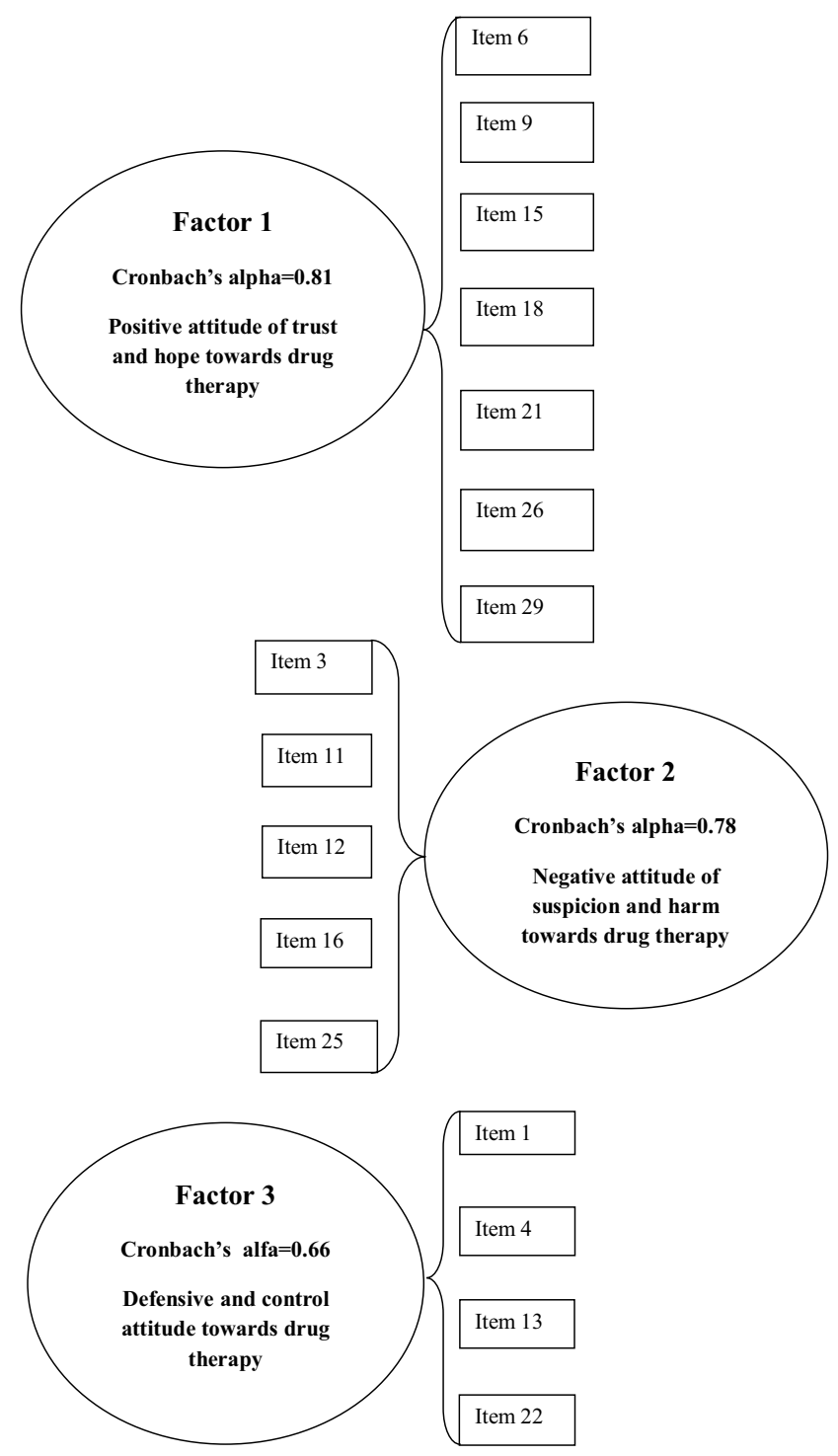

Figure 4 The three factors of DAl-30.

suggesting the "patients' models of health". Our EFA results overlap the Italian validation study, ${ }^{45}$ although, among the 7 Factors highlighted by this study, only the first two were loaded by most items and explained the majority of the variance. These results confirm DAI-30 validity over time in showing the patients' attitudes and experiences regarding drug therapy, which is apparently unchanged after 37 years from the inventory construction. Moreover, since we obtained the same results as the DAI-30 authors, who differently from us applied the inventory in a sample of patients affected by schizophrenia, we can infer that the attitude towards drug therapy can be similar in different psychiatric disorders, representing a universal perception and experience of drug therapy. 
Table 5 Variables Statistically Significantly Related to the DAI-30 Total and Factor Scores (Stepwise Multiple Linear Regression Model)

\begin{tabular}{|c|c|c|c|c|}
\hline Variable & Coefficient & $\begin{array}{l}\text { Standard } \\
\text { Error }\end{array}$ & Probability & $\begin{array}{l}\text { 95\% Confidence } \\
\text { Interval }\end{array}$ \\
\hline \multicolumn{5}{|l|}{ The DAl-30 total score } \\
\hline $\begin{array}{l}\text { Number of psychiatric hospitalizations from } \\
\text { illness onset }\end{array}$ & -0.32 & 0.15 & $p=0.033$ & $-0.62 ;-0.02$ \\
\hline $\begin{array}{l}\text { Mono/Polytherapy } \\
\text { ("Polytherapy")* } \\
\text { "Monotherapy" }\end{array}$ & -4.24 & 1.54 & $p=0.007$ & $-7.29 ;-1.19$ \\
\hline $\begin{array}{l}\text { Marital status } \\
(\text { ("single")* } \\
\text { "married" }\end{array}$ & 2.87 & 1.34 & $p=0.034$ & $0.22 ; 5.53$ \\
\hline \multicolumn{5}{|l|}{ Factor I score } \\
\hline $\begin{array}{l}\text { Number of psychiatric hospitalizations from } \\
\text { illness onset }\end{array}$ & -1.25 & 0.47 & $P=0.008$ & $-2.17 ; 0.33$ \\
\hline $\begin{array}{l}\text { Therapy with antipsychotic drugs } \\
\text { ("present")* } \\
\text { "absent" }\end{array}$ & -2.24 & 0.61 & $p=0.000$ & $-3.44 ;-1.03$ \\
\hline \multicolumn{5}{|l|}{ Factor 2 score } \\
\hline $\begin{array}{l}\text { Work } \\
\text { (“employed")* } \\
\text { Retired for age } \\
\text { Student }\end{array}$ & $\begin{array}{l}-1.23 \\
-2.16\end{array}$ & $\begin{array}{l}0.60 \\
0.81\end{array}$ & $\begin{array}{l}p=0.042 \\
p=0.009\end{array}$ & $\begin{array}{l}-2.42 ;-0.046 \\
-3.77 ;-0.55\end{array}$ \\
\hline \multicolumn{5}{|l|}{ Factor 3 score } \\
\hline $\begin{array}{l}\text { Treatment in other community services ("present")* } \\
\text { "absent" }\end{array}$ & -0.73 & 0.33 & $\mathrm{P}=0.027$ & $-1.38 ;-0.08$ \\
\hline
\end{tabular}

Notes: *Reference variable

The overall score obtained $(14.24 \pm 10.46)$ in our sample indicates a moderately positive attitude towards drug therapy. It suggests an attitude of trust in drug prescription and, indirectly, in therapeutic relationship with therapists of CMHC. This result is consistent with the literature, which reports higher scores in stabilized outpatient and in long-term care patients, characteristics presented by our participants ${ }^{51,63}$ and lower scores in hospitalized and/or acute illness patients. ${ }^{14,65}$ We did not find any statistically significant difference in the DAI-30 score between patients suffering from schizophrenic spectrum disorders and those suffering from all other diagnoses. This result suggests that the attitude evaluated through the DAI-30 is not specific to the individuals affected by schizophrenic spectrum disorders but it is similarly present in patients suffering from other subacute psychiatric disorders treated in an outpatient service.
In our multiple linear regression, two variables, "number of psychiatric hospitalizations from the illness onset" and "monotherapy", were negatively statistically significantly correlated with the DAI-30 score, whereas the marital status "married" was positively statistically significantly correlated with the DAI-30 score. Each of the three factors we identified was significantly and negatively related to different variables, suggesting that "previous psychiatric hospitalizations" and "no antipsychotic drug therapy" could be associated with reduced positive attitude (Factor 1); whereas being "retired for age" and being a "student" could be associated with reduced negative attitude (Factor 2) and no treatment in other community service with reduced defensive and control attitude towards drugs (Factor 3). These results suggest the specificity of the dimensions represented by the three factors that are differently conditioned: the positive attitude (Factor 1) by clinical variables; the negative attitude 
(Factor 2) by socio-demographic ones; the defensive and control attitude (Factor 3) by organizational ones.

These results are partially in line with the literature. Being married or having a family is a well-known protective factor for the onset and prognosis of various psychiatric disorders either among schizophrenia spectrum ${ }^{30,38}$ or mood disorders. ${ }^{66,67}$ Family support has been identified as a protective factor for therapeutic adherence in another study that used the DAI-30. ${ }^{52}$ The number of previous psychiatric hospitalizations has been identified by most studies as a factor that does not favour a positive attitude towards drug therapy. ${ }^{20,21,26,27,50,68}$ This correlation indirectly indicates the key role of therapeutic adherence in avoiding repeated hospitalizations with the risk of aggravating the illness course and increasing health care costs.

The positive correlation between polypharmacy and DAI-30 score appears, at first glance, paradoxical and in contrast with what emerged in the literature: the taking of a polytherapy is accompanied by less manageability and greater side effect, is often associated with reduced therapeutic adherence and not recommended by the main international guidelines. ${ }^{69-71}$ The possible efficacy of a polypharmacy regime compared to monotherapy in particular clinical conditions is still a controversial topic in the literature. ${ }^{72}$ Although international guidelines recommend the prescription of antipsychotics in polypharmacy only as at last step, ${ }^{73}$ in case of resistance and in particularly severe forms, this practice is very common, particularly in outpatient and long-term settings. The positive attitude towards polytherapeutic regimes shown by our sample can be interpreted in light of the complexity and ambivalence feeling which often characterizes the therapeutic relationship between the patient and the therapists at CMHC. We can hypothesize that patients treated long term in an outpatient setting and in good clinical compensation (as evidenced by the low rate of hospitalizations in the previous year), had developed over time a good acceptability of pharmacological therapy. Moreover, they appeared to show such extreme trust in its efficacy as to overcome the negative counterpart represented by side effects and stigma potentially related to drug therapy. A similar result was recently highlighted by Rej et $\mathrm{al}^{63}$ the Dutch team, using DAI-30 in a cross-sectional study, which showed that 78 patients with bipolar disorder over the age of 60 who were treated with lithium had a more favourable attitude towards drug therapy compared to others not treated with lithium. This result was explained by the authors with the greatest benefit obtained by the positive action of lithium compared to its adverse effects. We hypothesize that in our sample, drug therapy assumed such positive and gratifying, and perhaps magically symbolic values, as to overcome the difficulty of taking complex polytherapy. On the other hand, our results suggest the possibility that a long-term therapeutic relationship, as in our patients, can induce an attitude of relational dependence on the therapist and, indirectly, on drug prescription and administration, and, symbolically, on the whole CMHC. Drugs could represent a symbolic representation of a significant figure such as the physician, if not even a surrogate of the therapists during their absence in a sort of transference phenomenon. ${ }^{74}$ Our results show that the perception of drug therapy can represent what the patient thinks of disease, the patient's expectations and hopes, but, at the same time, it expresses how much the therapist is able to accept patient needs in an empathic way. Therefore, drug therapy can represent an ambivalent object, invested by both the patient and the physician with expectations and hope for future improvement. Both drug prescription and administration can assume opposite clinical meanings ranged between the empathic sharing of the patient's needs and the therapeutic distancing from them, but, in any case, they are aimed at counteracting the disease. ${ }^{74}$ Drug therapy prescription can represent the climate and the organisation of therapeutic settings, able to modify not only the patient's condition but also the setting itself. The complex psycho-pharmacological therapeutic relationship does not only modify the clinical effect of the drug, but can strongly condition the patient's ability to adhere to a treatment plan, in which drug therapy is present as a central and indispensable part.

This leads us to highlight the importance of therapeutic alliance between the patient and the therapist and the need for constant attention to the patient's internal experience with drug therapies. DAI-30 can be a good predictor of adherence, since it explores the treatment experiences and healing expectations of patients and indirectly puts in evidence their insight and awareness of illness. All these factors together can strongly condition therapeutic adherence, as reported by other studies. ${ }^{43}$ In accordance with other authors, who proposed a patient-centered model of medication adherence, we report that "first step in finding solutions for nonadherence is understanding patient motives for taking or not taking prescribed medications". ${ }^{75}$

In light of our results, we remind that the patient experience with drug therapy should be periodically but regularly reviewed not only to avoid non-adherence behaviour, but also to reduce the psychological dependence on drug therapy and psychiatric service, which, although initially necessary in 
many cases in order to implement rehabilitative and psychotherapeutic programs, ${ }^{76}$ can reinforce regressive tendencies.

\section{Limitations and Advantages of the Study}

Our study has some limitations. First, the cross-sectional observational design of this study did not allow us to infer causality among the variables observed. In particular, the heterogeneity of psychiatric clinical disorders in our sample, which implies difference in treatment complexity and therapeutic adherence, makes our results not exhaustively interpretable. Furthermore, the DAI-30 score was not compared with symptom severity or outcome scales or other factors such as therapy interruption or psychiatric hospitalizations, which could have indicated in detail the correlation between disease severity and therapeutic adherence. Other studies focused on correlation between clinical factor and DAI score can deepen its predictability in therapeutic adherence and, indirectly, clinical outcome.

On the other hand, the strengths already mentioned are represented by the sample size and the inclusion in the same sample of patients with different psychiatric diagnoses, representative of the patients treated in our community mental health service.

\section{Conclusions}

This study confirms that the DAI-30 is a reliable tool, easy to administer and to understand, which analyses three different dimensions of attitude towards drug therapy: trust and hope, suspicion and fear of harm, defence and control, in accordance with our factorial analysis.

We highlighted a good emotional and therapeutic atmosphere in our $\mathrm{CMHC}$, suggested by the positive score of the DAI-30 and the high rate of participation in the study, both potential indicators of therapeutic adherence. The correlations between the DAI-30 scores and the selected socio-demographic and clinical variables indicate that the positive attitude towards drug therapy can be reinforced by family support and reduced by relapses with hospitalization, as literature has highlighted. Paradoxically, in our sample, polytherapy favoured a positive attitude towards drugs. This last result suggests a sort of psychological dependence on drug therapy and, indirectly, on psychiatric service, that can be explained by the long-term treatments of our patients.
Our results lead us to reflect on the risks of dependence on drugs, especially in long-term treatments in a community service setting. Therapists must be aware of this risk and constantly monitor drug prescription within the therapeutic relationship. The meaning that drug therapy assumes for the patient should be correctly and periodically re-evaluated by all members of the multidisciplinary team of a community psychiatric service. In particular, the attitude towards drugs can be an important indicator not only of the patient's expectations and illness awareness, but also of the therapists' ability to create a non-stigmatizing therapeutic relationship aimed at the patient's autonomy and responsibility.

Future longitudinal studies are necessary to deepen the understanding of such a complex and multifactorial phenomenon as the attitude towards pharmacological therapy in order to implement more appropriate strategies to prevent the patients' abandonment of treatments and, at the same time, their dependence on therapy and psychiatric service.

\section{Disclosure}

The authors report no actual or potential conflicts of interest.

\section{References}

1. World Health Organization. Adherence to long-term therapies. Evidence for action. Gineva: WHO; 2003. Available from: http:// www.who.int/chp/knowledge/publications/adherence_report/en/. Accessed April 13, 2020.

2. National Institute for Health and Clinical Excellence. Medicines adherence involving patients in decisions about prescribed medicines and supporting adherence. NICE clinical guideline n. 76; 2009. Available from: http://www.nice.org.uk/guidance/CG76. Accessed April 13, 2020.

3. Williams A, Manias E, Walker R. Interventions to improve medication adherence in people with multiple chronic condition: a systematic review. $J$ Adv Nurs. 2008;63(2):132-143. doi:10.1111/j.13652648.2008.04656.x

4. Sirois BC, Burg MM. Negative emotion and coronary heart disease. A review. Behav Modif. 2003;27(1):83-102. doi:10.1177/ 0145445502238695

5. Colivicchi F, Abrignani MG, Santini M. Aderenza terapeutica: il fattore di rischio occulto. [Therapeutic adherence: a hidden risk factor]. G Ital Cardiol. 2010;11(5 Suppl 3): 124S-127S. doi:10.1714/ 576.6834

6. Baroletti S, Dell'Orfano H. Medication adherence in cardiovascular disease. Circulation. 2010;121(12):1455-1458. doi:10.1161/ CIRCULATIONAHA.109.904003

7. Osterberg L, Blaschke T. Adherence to medication. $N$ Engl J Med. 2005;353(5):487-497. doi:10.1056/NEJMra050100

8. Dunbar-Jacob J, Erlen JA, Schlenk EA, Ryan CM, Sereika SM, Doswell WM Adherence in chronic disease. Annu Rev Nurs Res. 2000;18:48-90. doi:10.1891/0739-6686.18.1.48

9. Rybacki JJ. Improving cardiovascular health in postmenopausal women by addressing medication adherence issues. J Am Pharm Assoc. 2002;42(1):63-71. doi:10.1331/108658002763538099 
10. Semahegn A, Torpey K, Manu A, Assefa N, Tesfaye G, Ankomah A. Psychotropic medication non-adherence and associated factors among adult patients with major psychiatric disorders: a protocol for a systematic review. Systematic Reviews. 2018;7:10. doi:10.1186/s13643-018-0676-y

11. Balestrieri M, Bellantuono C, Berardi D, et al. Manuale di Psichiatria. [Manual of Psychiatry] Roma: Il Pensiero Scientifico Editore; 2014. Italian.

12. Cramer JA, Rosenheck R. Compliance with medication regimens for mental and physical disorders. Psychiatr Serv. 1998;49(2):196-201. doi:10.1176/ps.49.2.196

13. Lacro JP, Dunn LB, Dolder CR, Leckband SG, Jeste DV. Prevalence of and risk factors for medication nonadherence in patients with schizophrenia: a comprehensive review of recent literature. J Clin Psychiatry. 2002;63(10):892-909. doi:10.4088/JCP.v63n1007

14. Medina E, Salvà J, Ampudia R, Maurino J, Larumbe J. Short-term clinical stability and lack of insight are associated with a negative attitude towards antipsychotic treatment at discharge in patients with schizophrenia and bipolar disorder. Patient Prefer Adherence. 2012; 6:623-629. doi: 10.2147/PPA.S34345

15. Rossi A, Stratta P, Arduini A. Compliance with antipsychotic medication. Italian J Psychopathol. 2002;8(4):391-400.

16. Klingberg S, Schneider S, Wittorf A, Buchkremer G, Wiedemann G. Collaboration in outpatient antipsychotic drug treatment: analysis of potentially influencing factors. Psychiatry Res. 2008;161(2):225-234. doi:10.1016/j.psychres.2007.07.027

17. Lauzier S, Grégoire JP, Lesage A, Moisan J. Community pharmacy loyalty among individuals with schizophrenia. Res Social Adm Pharm. 2013;9(6):806-816. doi:10.1016/j.sapharm.2013.01.007

18. Zipursky R, Menezes N, Streiner D. Risk of symptom recurrence with medication discontinuation in first-episode psychosis: a systematic review. Schizophr Res. 2014;152:408-414. doi:10.1016/j.schres.2013.08.001.19

19. Di Lorenzo R, Cameli M, Piemonte C, et al. Clinical improvement, relapse and treatment adherence with paliperidone palmitate 1-month formulation: 1-year treatment in a naturalistic outpatient setting. Nord J Psychiatry. 2018;72(3):214-220. doi:10.1080/08039488.2017.1420819

20. Haddad PM, Brain C, Scott J. Nonadherence with antipsychotic medication in schizophrenia: challenges and management strategies. Patient Relat Outcome Meas. 2014;5:43-62. doi:10.2147/PROM.S42735

21. Di Lorenzo R, Sagona M, Landi G, Martire L, Piemonte C, Del Giovane C. The revolving door phenomenon in an Italian acute psychiatric ward: a 5-year retrospective analysis of the potential risk factors. J Nerv Ment Dis. 2016;204(9):686-692. doi:10.1097/ NMD.0000000000000540

22. Brain C, Allerby K, Sameby B, et al. Drug attitude and other predictors of medication adherence in schizophrenia: 12 months of electronic monitoring (MEMS $\left({ }^{\circledR}\right)$ ) in the Swedish COAST-study. Eur Neuropsychopharmacol. 2013;23(12):1754-1762. doi:10.1016/j. euroneuro.2013.09.001

23. Ascher-Svanum H, Faries DE, Zhu B, Ernst FR, Swartz MS, Swanson JW. Medication adherence and long-term functional outcomes in the treatment of schizophrenia in usual care. $J$ Clin Psychiatry. 2006;67(3):453-460. doi:10.4088/JCP.v67n0317

24. Novick D, Haro JM, Suarez D, Perez V, Dittmann RW, Haddad PM. Predictors and clinical consequences of non-adherence with antipsychotic medication in the outpatient treatment of schizophrenia. Psychiatry Res. 2010; 176(2-3):109-113. doi:10.1016/j.psychres.2009.05.004

25. Hayhurst KP, Drake RJ, Massie JA, et al. Improved quality of life over one year is associated with improved adherence in patients with schizophrenia. Eur Psychiatry. 2014;29(3):191-196. doi:10.1016/j. eurpsy.2013.03.002

26. Hong J, Reed C, Novick D, Haro JM, Aguado J. Clinical and economic consequences of medication non-adherence in the treatment of patients with a manic/mixed episode of bipolar disorder: results from the European Mania in Bipolar Longitudinal Evaluation of Medication (EMBLEM) study. Psychiatry Res. 2011;190(1):110-114. doi:10.1016/j.psychres.2011.04.016
27. García S, Martínez-Cengotitabengoa M, López-Zurbano S, et al. Adherence to antipsychotic medication in bipolar disorder and schizophrenic patients. A systematic review. J Clin Psychopharmacol. 2016;36(4):355-371. doi:10.1097/JCP.0000000000000523

28. De Las Cuevas C, Peñate W, Manuel García de Cecilia J, de Leon J. Predictive validity of the Sidorkiewicz instrument in Spanish: assessing individual drug adherence in psychiatric patients. Int $\mathrm{J}$ Clin Health Psychol. 2018;18(2):133-142. doi:10.1016/j.ijchp.2017.11.003

29. Velligan DI, Sajatovic M, Hatch A, Kramata P, Docherty JP. Why do psychiatric patients stop antipsychotic medication? A systematic review of reasons for nonadherence to medication in patients with serious mental illness. Patient Prefer Adherence. 2017;11:449-468. doi:10.2147/PPA.S124658

30. Baloush-Kleinman V, Levine SZ, Roe D, Shnitt D, Weizman A, Poyurovsky M. Adherence to antipsychotic drug treatment in early-episode schizophrenia: a six-month naturalistic follow-up study. Schizophr Res. 2011;130 (1-3):176-181. doi:10.1016/j. schres.2011.04.030

31. Mohamed S, Rosenheck R, McEvoy J, Swartz M, Stroup S, Lieberman JA. Cross-sectional and longitudinal relationships between insight and attitudes toward medication and clinical outcomes in chronic schizophrenia. Schizophr Bull. 2009;35 (2):336-346. doi:10.1093/schbul/sbn067

32. Beck EM, Cavelti M, Kvrgic S, Kleim B, Vauth R. Are we addressing the 'right stuff' to enhance adherence in schizophrenia? Understanding the role of insight and attitudes towards medication. Schizophr Res. 2011;132(1):42-49. doi:10.1016/j.schres.2011.07.019

33. Wong MM, Chen EY, Lui SS, Tso S. Medication adherence and subjective weight perception in patients with first-episode psychotic disorder. Clin Schizophr Relat Psychoses. 2011;5(3):135-141. doi:10. 3371/CSRP.5.3.3

34. Kamali M, Kelly BD, Clarke M, et al. A prospective evaluation of adherence to medication in first episode schizophrenia. Eur Psychiatry. 2006;21(1):29-33. doi:10.1016/j.eurpsy.2005.05.015

35. Ascher-Svanum H, Zhu B, Faries D, Lacro JP, Dolder CR. A prospective study of risk factors for nonadherence with antipsychotic medication in the treatment of schizophrenia. $J$ Clin Psychiatry. 2006;67(7):1114-1123. doi:10.4088/JCP.v67n0715

36. González-Pinto A, Reed C, Novick D, Bertsch J, Haro JM. Assessment of medication adherence in a cohort of patients with bipolar disorder. Pharmacopsychiatry. 2010;43(7):263-270. doi:10. 1055/s-0030-1263169

37. Miller R, Ream G, McCormack J, Gunduz-Bruce H, Sevy S, Robinson D. A prospective study of cannabis use as a risk factor for non-adherence and treatment dropout in first-episode schizophrenia. Schizophr Res. 2009;113 (2-3):138-144. doi:10.1016/j.schres.2009.04.018

38. Rabinovitch M, Béchard-Evans L, Schmitz N, Joober R, Malla A. Early predictors of nonadherence to antipsychotic therapy in first-episode psychosis. Can J Psychiatry. 2009;54(1):28-35. doi:10.1177/070674370905400106

39. Magura S, Rosenblum A, Fong C. Factors associated with medication adherence among psychiatric outpatients at substance abuse risk. Open Addict J. 2011;4:58-64. doi:10.2174/1874941001104010058

40. Sapra M, Weiden PJ, Schooler NR, Sunakawa-McMillan A, Uzenoff S, Burkholder P. Reasons for adherence and nonadherence: a pilot study comparing first- and multi-episode schizophrenia patients. Clin Schizophr Relat Psychoses. 2014;7(4):199-206. doi:10.3371/CSRP.SAWE.020813

41. Lee Y, Lee MS, Jeong HG, Youn HC, Kim SH. Medication Adherence Using Electronic Monitoring In Severe Psychiatric Illness: 4 and 24 weeks after discharge. Clin Psychopharmacol Neurosci. 2019;17 (2):288-296. doi:10.9758/cpn.2019.17.2.288

42. Tessier A, Boyer L, Husky M, Baylé F, Llorca PM, Misdrahi D. Medication adherence in schizophrenia: the role of insight, therapeutic alliance and perceived trauma associated with psychiatric care. Psychiatry Res. 2017;257:315-321. doi:10.1016/j.psychres.2017.07.063 
43. Barkhof E, Meijer CJ, de Sonneville LM, Linszen DH, de Haan L. Interventions to improve adherence to antipsychotic medication in patients with schizophrenia-a review of the past decade. Eur Psychiatry. 2012;27(1):9-18. doi:10.1016/j.eurpsy.2011.02.005

44. Hogan TP, Awad AG, Eastwood R. A self-report scale predictive of drug compliance in schizophrenics: reliability and discriminative validity. Psychol Med. 1983;13(1):177-183. doi:10.1017/S0033291700050182

45. Rossi A, Arduini L, De Cataldo S, Stratta P. Subjective response to neuroleptic medication: a validation study of the Italian version of the Drug Attitude Inventory (DAI). Epidemiol Psichiatr Soc. 2001;10 (2):107-114. doi:10.1017/S1121189X00005182

46. Yoon BH, Bahk WM, Lee KU, Hong CH, Ahn JK, Kim MK. Psychometric properties of Korean version of drug attitude inventory (KDAI-10). Korean J Psychopharmacol. 2005;16(6):480-487. Korean.

47. Aydin E, Aydin E, Balaban ÖD, Yumrukçal H, Erkiran M. The validity and reliability of the Turkish version of drug attitude inventory-10. Noro Psikiyatr Ars. 2018;55(3):238-242. doi:10.5152/ npa.2017.18078

48. Khalil AH, ELNahas G, Ramy H, Abdel Aziz K, Elkholy H, ElGhamry R. Impact of a culturally adapted behavioural family psychoeducational programme in patients with schizophrenia in Egypt. Int J Psychiatry Clin Pract. 2019;23(1):62-71. doi:10.1080/13651 501.2018.1480786

49. Nakhli J, Amamou B, Mlika S, et al. Cultural translation and Tunisian validation of the Drug Attitude Inventory (DAI-30) in outpatients with schizophrenia. Compr Psychiatry.2015;56:69-74. doi:10.1016/j.comppsych.2014.09.002

50. Townsend L, Floersch J, Findling RL. Adolescent attitudes toward psychiatric medication: the utility of the Drug Attitude Inventory. J Child Psychol Psychiatry. 2009;50(12):1523-1531. doi:10.1111/ j.1469-7610.2009.02113.x

51. Balestrieri M, Di Sciascio G, Isola M, et al. Drug attitude and subjective well-being in antipsychotic treatment monotherapy in real-world settings. Epidemiol Psichiatr Soc. 2009;18(2):114-118. doi:10.1017/S1121189X00000993

52. Dassa D, Boyer L, Benoit M, Bourcet S, Raymondet P, Bottai T. Factors associated with medication non-adherence in patients suffering from schizophrenia: a cross-sectional study in a universal coverage health-care system. Aust N Z J Psychiatry. 2010;44(10):921-928. doi: 10.3109/00048674.2010.493503

53. Dahan S, Behrbalk P, Stolovy T, Greenberger C. Improving adherence in hospitalized patients diagnosed with schizophrenia: an integrative one-on-one intervention. Arch Psychiatr Nurs. 2016;30 (6):660-665. doi:10.1016/j.apnu.2016.03.002

54. Ministry of Labor, Health and Social Policies. Classification of Diseases, Traumatisms, Surgical Interventions and Diagnostic and Therapeutic Procedures: Italian Version of the ICD-9-CM (International Classification of Diseases, 9th Revision, Clinical Modification, 2007). Rome: Istituto poligrafico e Zecca dello Stato, Libreria dello Stato; 2008.

55. Crawford CB, Ferguson GA. A general rotation criterion and its use in orthogonal rotation. Psychometrika. 1970;35(3):321-332. doi:10.1007/BF02310792

56. Bentler PM. Factor simplicity index and transformations. Psychometrika. 1977;42(2):277-295. doi:10.1007/BF02294054

57. Kaiser HF. The varimax criterion for analytic rotation in factor analysis. Psychometrika. 1958;23:187-200. doi:10.1007/BF02289233

58. Kaiser HF. An index of factorial simplicity. Psychometrika. 1974;39 (1):31-36. doi:10.1007/BF02291575

59. Tabachnick BG, Fidell LS. Using Multivariate Statistics. Boston: Pearson/Allyn \& Bacon; 2007.
60. Bryant FB, Yarnold PR. Principal-components analysis and exploratory and confirmatory factor analysis. In: Grimm G, RR Y, editors. Reading and Understanding Multivariate Statistics. Washington, DC, US: American Psychological Association; 1995.

61. Thunander Sundbom L, Bingefors K, Hedborg K, Isacson D. Are men under-treated and women over-treated with antidepressants? Findings from a cross-sectional survey in Sweden. BJPsych Bull. 2017;41(3):145-150. doi:10.1192/pb.bp.116.054270

62. Maust DT, Lin LA, Blow FC. Benzodiazepine use and misuse among adults in the United States. Psychiatr Serv. 2019;70(2):97-106. doi:10.1176/appi.ps.201800321

63. Rej S, Schuurmans J, Elie D, Stek ML, Shulman K, Dols A. Attitudes towards pharmacotherapy in late-life bipolar disorder. Int Psychogeriatr. 2016;28(6):945-950. doi:10.1017/S1041610215002380

64. Barbui C, Papola D, Saraceno B. Forty years without mental hospitals in Italy. Int J Ment Health Syst. 2018;12:43. doi:10.1186/s13033018-0223-1

65. Day JC, Bentall RP, Roberts C, et al. Attitudes toward antipsychotic medication: the impact of clinical variables and relationships with health professionals. Arch Gen Psychiatry. 2005;62(7):717-724. doi:10.1001/archpsyc.62.7.717

66. Scott KM, Wells JE, Angermeyer M, et al. Gender and the relationship between marital status and first onset of mood, anxiety and substance use disorders. Psychol Med. 2010;40(9):1495-1505. doi: $10.1017 /$ S0033291709991942

67. Biotteau AL, Bonnet C, Cambois E. Risk of major depressive episodes after separation: the gender-specific contribution of the income and support lost through union dissolution. Eur J Popul. 2019;35 (3):519-542. doi:10.1007/s10680-018-9488-y

68. De Las Cuevas C, Peñate W, Sanz EJ. Risk factors for non-adherence to antidepressant treatment in patients with mood disorders. Eur J Clin Pharmacol. 2014;70(1):89-98. doi:10.1007/s00228-013-1582-9

69. Lehman AF, Lieberman JA, Dixon LB, et al. American Psychiatric Association; Steering Committee on Practice Guidelines. Practice guideline for the treatment of patients with schizophrenia, second edition. Am J Psychiatry. 2004;161(2 Suppl):1-56.

70. Miller AL, Craig CS. Combination antipsychotics: pros, cons, and questions. Schizophr Bull. 2002;28(1):105-109. doi:10.1093/oxfordjournals.schbul.a006912

71. Lochmann van Bennekom MW, Gijsman HJ, Zitman FG. Antipsychotic polypharmacy in psychotic disorders: a critical review of neurobiology, efficacy, tolerability and cost effectiveness. J Psychopharmacol. 2013;27(4):327-336. doi:10.1177/0269881 113477709

72. Tiihonen J, Taipale H, Mehtälä J, Vattulainen P, Correll CU, Tanskanen A. Association of antipsychotic polypharmacy vs monotherapy with psychiatric rehospitalization among adult with schizophrenia. JAMA Psychiatry. 2019;76(5):499-507. doi:10.1001/ jamapsychiatry.2018.4320

73. Taylor DM, Barnes TRE, Young AH. The Maudsley Prescribing Guidelines in Psychiatry. 13th ed. UK: Wiley Blackwell; 2018.

74. Riefolo G. Psichiatria prossima. La psichiatria territoriale in un'epoca di crisi. [Next psychiatry. The community psychiatry in a period of crisis]. Torino:Boringhieri Bollati Editore; 2001. Italian.

75. Kikkert MJ, Dekker J. Medication adherence decisions in patients with schizophrenia. Prim Care Companion CNS Disord. 2017;19(6). pii:17n02182. doi:10.4088/PCC.17n02182

76. Bonavigo T, Sandhu S, Pascolo-Fabrici E, Priebe S. What does dependency on community mental health services mean? A conceptual review with a systematic search. Soc Psychiatry Psychiatr Epidemiol. 2016;51:561-574. doi:10.1007/s00127-016-1180-0 


\section{Publish your work in this journal}

Patient Preference and Adherence is an international, peer-reviewed, open access journal that focuses on the growing importance of patient preference and adherence throughout the therapeutic continuum. Patient satisfaction, acceptability, quality of life, compliance, persistence and their role in developing new therapeutic modalities and compounds to optimize clinical outcomes for existing disease states are major areas of interest for the journal. This journal has been accepted for indexing on PubMed Central. The manuscript management system is completely online and includes a very quick and fair peer-review system, which is all easy to use. Visit http:// www.dovepress.com/testimonials.php to read real quotes from published authors.

Submit your manuscript here: https://www.dovepress.com/patient-preference-and-adherence-journal 